\title{
Heard immunity: effective persuasion for a future COVID-19 vaccine
}

\author{
Nicolas Duquette ${ }^{1}$ \\ *University of Southern California, Sol Price School of Public Policy, nduquett@usc.edu
}

September 4, 2020

\begin{abstract}
A survey experiment exposes treatment groups to four messages supporting future vaccination against COVID-19. These treatments emphasize either the risks of the virus or the safety of vaccination, to the respondent personally or to others. For a nationally representative sample, self-reported intent to vaccinate is not significantly different from the control for any message. However, there is a substantial divergence between white non-Hispanic respondents, whose response to all four treatments is close to zero, and non-white or Hispanic respondents, whose intention to vaccinate is over 50\% higher in response to a message emphasizing pro-sociality and the safety of others.
\end{abstract}

\section{Keywords : Vaccination, COVID-19, survey experiments}

JEL Classification : D91, H51, I18

Acknowledgments: I am grateful for advice on the design of this experiment from John Romley, Anya Samek, Neeraj Sood, and Joanna Duquette, and from the amazing team at the Understanding America Survey. This research was funded using my discretionary faculty research account, for which I am very grateful to the USC Price School of Public Policy. All mistakes are the author's. 


\section{Vaccine hesitancy could make this pandemic longer and worse}

The COVID-19 pandemic will only end permanently when the population reaches herd immunity. If this is to happen without hundreds of millions of deadly and dangerous infections, a vaccine must be developed and widely used, quickly. Each person who successfully acquires immunity from a safe and effective vaccine not only avoids their own infection but also slows community spread of the virus.

Even if a safe and effective vaccine is discovered and tested quickly, however, a large minority of Americans may not take it, and policies to coerce vaccination may backfire. The decentralized structure and libertarian ethos of US institutions have historically caused the US to lag peer countries in containment of epidemic disease (Troesken 2015). Anti-vaccine activists exploit these institutions to resist immunization mandates (Reich 2018). Furthermore, even people who are ordinarily supportive of vaccination may not want the COVID-19 vaccine, if they do not trust that its safety has been adequately tested. For example, distrust of the American health system in general is widespread among Black Americans as a result of historical patterns of medical exploitation, causing reduced uptake of life-saving preventive health measures (Alsan and Wanamaker 2017), 1 Furthermore, because children and young adults are at lower risk from COVID-19, the coercive policy most widely and successfully used in the US-school vaccination requirements-would not directly protect the most endangered groups.

Since coercive policies are unlikely to be effective, uptake of the COVID-19 vaccine in the US may depend on finding a message that will successfully persuade the vaccine-hesitant to get their shot. The survey experiment described in this paper tests four messages for effects on respondents' self-reported intention to vaccinate when a vaccine becomes available.

The effect of the messages varies starkly by race and ethnicity. For the complete, nationally representative sample, no message has a statistically significant effect relative to a control group. This is because non-Hispanic white respondents are unresponsive to all messages, with point estimates consistently close to zero. But for non-white and Hispanic respondents, the messages have sizable estimated treatment effects: the most effective message, one emphasizing vaccine safety and protection of others, increases this group's intention to vaccinate by $50.4 \%$.

This heterogeneous treatment effect is explained by varying reasons for vaccine hesitancy. Non-Hispanic white respondents are more likely than others to express lack of fear of the COVID19 illness, and thus less likely to see any need for a vaccine. Non-white and Hispanic/Latino respondents are more likely than non-Hispanic whites to hesitate because of fears that the COVID19 vaccine itself will be unsafe or because it will cost too much.

This heterogeneous treatment effect is important for the general public health and for equity:

\footnotetext{
${ }^{1}$ Herd immunity may also be difficult to reach if there are many people who would be willing to vaccinate but are deterred by other factors. For example, cost and access to health services affect vaccination rates. While many other preventive health measures are not cost-sensitive, (Kolstad and Kowalski 2012 table 4) find that seasonal influenza vaccine uptake is an exception. The out-of-pocket cost of any COVID-19 vaccine may therefore also affect uptake. Also, vaccines are contraindicated for people with immune system disorders and other health risks, which means herd immunity must arise from coverage within the remaining population.
} 
Black, Native, and Latino Americans exhibit higher vaccine hesitancy than other groups, and have suffered higher infection and death rates from COVID-19 (Yancy 2020; Tai et al. 2020). A messaging campaign that increases vaccine uptake in this population could therefore have important public health benefits without any effect on non-Hispanic white uptake.

\section{Research Design}

This study uses a survey experiment to examine the effects of COVID-19 vaccine messaging on intended uptake. Messaging has been demonstrated to effectively increase vaccine compliance in other contexts; for example, simple differences in the ways pediatricians frame vaccination increases compliance with the pediatric vaccine schedule (Opel et al. 2013). Historically, public health officials have experimented with messages emphasizing the personal benefits conferred by vaccination on oneself and one's family, or the social duty of vaccine compliance (Colgrove 2006 Reich 2018), but we know little about which of these was more effective. Therefore, it is an open question whether the kind of messages that persuade parents to vaccinate their children against now-uncommon diseases will be the most effective in the context of a deadly viral pandemic.

\subsection{A two-by-two message design}

Four messages are structured to emphasize the risks of the virus or the safety of the vaccine, from the perspective of self-interest or of social responsibility. I join these two emphases and two perspectives into four messages using a two-by-two design. The same or similar sentences are combined across treatments to allow for clearer comparisons.2 The Risk-to-Self message emphasizes the danger the virus poses to those who are not immune:

It is important to vaccinate against COVID-19 because it is dangerous. The virus can harm the lungs, heart, brain, and other body systems. While elderly and ill people are at extra risk, COVID-19 is potentially deadly for anyone. Your vaccination protects you from death or severe illness.

It is logical that people would be more interested in vaccination when the risk of disease is higher. Previous research has shown that parents' compliance with pediatric vaccine schedules increases in response to local pertussis outbreaks (Oster 2018; Schaller et al. 2019). This response is likely driven by perceptions of risk and anticipated regret, which psychologists have found increase vaccine uptake (Brewer et al. 2017). In the specific context of COVID-19, Shoji et al. (2020) show that knowledge of heightened local infection risk increases social distancing behavior. Moreover, a survey experiment by Thunstrom et al. (2020) finds that risk communication increases intention to vaccinate against COVID-19 ${ }^{3}$ A message emphasizing the respondent's personal risk

\footnotetext{
${ }^{2}$ The full text of the experiment is presented in appendix A2 here I provide the messages only alongside explanations of their potential effectiveness.

${ }^{3}$ On the other hand, Akesson et al. (2020) find that perceptions of greater infectiousness of the virus lead to lower social distancing, apparently due to fatalism about the certainty of eventual infection.
} 
may therefore increase intent to vaccinate as well.

The Risk-to-Self message emphasizes the dangers posed by the virus and avoided by vaccination. The Safety-for-Self message keeps the first two sentences of Risk-to-Self but frames the benefit of vaccination in terms of the safety it allows, not the risk it avoids:

It is important to vaccinate against COVID-19 because it is dangerous. The virus can harm the lungs, heart, brain, and other body systems. Vaccination gives you immunity without illness. Your vaccination can keep you healthy and safe.

This message emphasizes a positive frame on the decision to vaccinate as well as the safety of vaccination itself. Positive and negative framing of otherwise equivalent public-goods games can lead to very different pro-social outcomes (Andreoni 1995), including in public goods games that explicitly model the decision to vaccinate (Sorensen 2019). Moreover, fear of adverse vaccine outcomes drives much of vaccine noncompliance, well out of proportion to the actual risks involved. For example, negative media coverage about the safety of the human papillomavirus (HPV) vaccine decreased uptake not only for that vaccine but for all vaccines among Danish girls (Gørtz et al. 2020). For these reasons, a message emphasizing safety to oneself could yield a very different response to one emphasizing risks of viral infection, even if the factual information conveyed is little different.

Instead of focusing on risks and benefits to individuals, successful messages may want to emphasize the prosocial role of vaccination. The benefit of a vaccine redounds partially to the patient, who becomes immune, and partially to society, which faces lower rates of community spread. There is reason to think that altruism is important for vaccination against a pandemic virus-Campos-Mercade et al. (2020) show for example that a pro-social orientation predicts a person's willingness to wear a face covering, practice social distancing, and to donate to a COVID-19 charity. On the other hand, qualitative research finds while that anti-vaccine activists understand the "free rider" dilemma of herd immunity, they dispute that they should consider this an important reason to vaccinate their children (Reich 2018 pp. 236-238).

The Risk-to-Others message emphasizes the dangers that low population immunity poses to other people. The first two sentences emphasize the role of immunity in preventing viral spread. The last two sentences are almost identical to those in the Risk-to-Self treatment, but modified to focus on the risk to other people:

It is important to vaccinate against COVID-19 because it is contagious. When a person becomes immune, they will not spread the virus to others. While elderly and ill people are at extra risk, COVID-19 is potentially deadly for everybody. Your vaccination protects others from death or severe illness.

Previous research has found that information about risks to others elicits behaviors to end the pandemic. Sjåstad and Van Bavel (2020) find that perceptions of risk to others correlate with greater intent to perform pro-social pandemic behaviors. Also, Abel et al. (2020) find that while providing information about the recipient's risk to healthy young people does not affect donations to a COVID-19 charity, information about risk to elderly people increases giving substantially. 
Lastly, the Safety-for-Others message combines the first two sentences of the Risk-to-Others message with a modified version of the last two sentences of the Safety-for-Self message, to deliver a message that emphasizes the pro-social externality of vaccination, in a frame that emphasizes keeping others safe:

It is important to vaccinate against COVID-19 because it is contagious. When a person becomes immune, they will not spread the virus to others. Vaccination gives you immunity without illness. Your vaccination can keep other people healthy and safe.

After viewing a randomly assigned message and expressing whether they intended to vaccinate against COVID-19, respondents were shown a follow-up question conditional on their answer. Respondents who indicated that they planned to get the vaccine were asked how quickly they planned to receive it $\left.\right|_{4} ^{4}$ Respondents who did not indicate that they planned to receive the vaccine were asked to indicate their reason for hesitancy from a checklist of possible answers.

\subsection{Survey implementation}

These messages were presented to a nationally representative survey panel, administered by the Understanding America Study (UAS), a program of the Center for Economic and Social Research at the University of Southern California. Respondents were randomized to five experimental arms. Four treatment arms viewed one of the messages; a control group saw no message. Each group was then asked whether they wanted the future COVID-19 vaccine. The survey identifier was UAS-299. The research plan was approved by the USC Internal Revenue Board with identifier UP-14-00148-AM080. Survey responses were collected from July 13 to July 21, 2020.

The UAS survey allows researchers to link anonymous respondents across survey waves. I oversample respondents who were previously unsure whether they wanted vaccination against COVID-19 using a question from March 2020 survey UAS-230, which asked respondents to estimate their probability of vaccinating. The sampling design set a goal of 2200 responses, with subgroup goals of 400 respondents with self-reported March vaccine probability of $0 \%, 1300$ respondents between 1 and 99\%, and 500 respondents at 100\%. UAS panel participants who did not answer UAS-230 were not invited to the survey. Analyses were rebalanced using survey probability weights to construct a nationally representative sample ${ }^{5}$

The UAS survey includes demographic information gathered as part of the design of the panel, including gender, age, race, Hispanic/Latino ethnicity, educational attainment, marital status, and US citizenship. Additionally, I add a variable for political partisanship by linking respondents to survey UAS-221, which asked respondents their registered political party in January 2020. This method identifies partisanship for all respondents except for 314 who did not participate in UAS-221.

\footnotetext{
${ }^{4}$ This follow-up question was motivated by worry that people who were marginal "yes" respondents might have low urgency, which would suggest the true effect on actual uptake might be overstated. However, there is no discernible difference in uptake urgency across treatment groups conditional on a yes answer.

${ }^{5}$ Additional regressions presented in appendix A1 table $\mathrm{A} 1$ demonstrate that the findings presented below are qualitatively the same in an equally weighted regression.
} 


\subsection{Analytical strategy}

The primary analytical method is a linear probability model where the outcome is coded as 1 for respondents who answer "yes" when asked whether they want the COVID-19 vaccine and 0 for answers of "no" or "maybe / I don't know." Treatment effects are estimated using a weighted least squares regression of the form

$$
\text { Yes }_{i}=\alpha+\sum_{t=1}^{4} \gamma_{t} \times \mathbf{1}\left\{\text { Treatment }_{i}=t\right\}+\mathbf{X}_{\mathbf{i}} \boldsymbol{\beta}+\varepsilon_{i}
$$

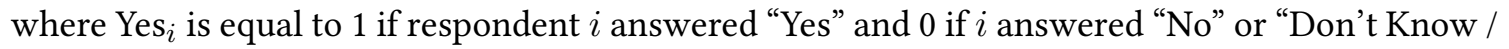
Not Sure." The coefficients of interest, denoted $\gamma_{t}$, are the differences in the yes-share for treatment $t$ relative to the control group. $\mathbf{X}_{\mathbf{i}}$ is a vector of control variables for demographics, education, partisanship, and March 2020 vaccine intent included in some specifications. The constant term $\alpha$ equals the yes-rate for the control group in specifications without additional controls. The residual is denoted $\varepsilon_{i}$.

This research design is preregistered in the American Economic Association randomized trial registry. Its unique identifying number is: "AEARCTR-0006133." A power analysis conducted as part of the preregistration suggests that the sampling design will reject the no-effect null for a true effect of $30 \%$ of a standard deviation at the $5 \%$ statistical significance level $80 \%$ of the time after adjusting for multiple hypothesis testing ${ }^{6}$

\section{Data}

The survey received 2,334 complete responses and 4 partial responses from 2,905 invitations, for a response rate of $80.34 \%$. Total usable responses were 2,336 . This exceeded the target sample of 2,200 due to a better-than-expected response rate.

Table 1 presents raw counts, weighted sample proportions, and intention-to-vaccinate rates for the sample. Average intention to vaccinate is worrisomely low, consistent with public polling and previous research (Thunstrom et al. 2020 ). 7 Weighting for a nationally representative sample, just over half of respondents definitely want to vaccinate against COVID-19. Roughly $20 \%$ do not want to vaccinate and $30 \%$ are unsure.

This represents a decline in vaccine intent since March 2020. Of people who stated that they were $100 \%$ sure they wanted a vaccine in March, only $72 \%$ answered "yes" in this survey. At the other extreme, just $4 \%$ of those who expressed a $0 \%$ chance of vaccination in March answered "yes" in July.

\footnotetext{
${ }^{6}$ This power calculation assumed that most respondents' probability of answering "yes" would be close to their stated probability in the March UAS survey. This is a conservative adjustment: a power calculation assuming each respondent would be an i.i.d. draw from a binomial distribution with 2200 identical and independent draws rejects the null more than $90 \%$ of the time for a treatment of $25 \%$ of a standard deviation.

${ }^{7}$ A Gallup poll administered over July 20 to August 2 found 35\% of Americans would refuse a free COVID-19 vaccine. (https://news.gallup.com/poll/317018/one-three-americans-not-covid-vaccine.aspx)
} 
Average intention to vaccinate varies widely by race and ethnicity. 75\% of Asian respondents express intention to vaccinate, but only $25 \%$ of Black respondents and $19 \%$ of Native Americans and Alaskan Natives. Latino and Hispanic respondents had higher intention to vaccinate than these groups (48\%), but still below the sample average. This is especially alarming considering that Black, Native, and Latino Americans have had much higher COVID-19 population mortality than other groups. White, Hawaiian/Pacific Islander, and bi-/multiracial respondents were close to the sample average, with a bit over half of each expressing intention to vaccinate.

Partisanship is correllated with intention to vaccinate. Democrats and Independents both express intention to vaccinate at higher rates (57\% and 56\%) than the sample average, while $47 \%$ of Republicans intend to get the vaccine. Minor-party members, such as registered Libertarians and Greens, have a low intention to vaccinate (31\%), although this is based on a small sample of just 25 respondents.

Intention to vaccinate increases in education, from $35 \%$ of respondents with less than a high school education, to $74 \%$ of respondents with graduate degrees. Intention to vaccinate by age is lowest for people in their 30s (42\%) and increasing in age thereafter, to a nearly $70 \%$ intention among people 70 and older. Men are more likely to plan to vaccinate than women (57\% versus $44 \%$ ), and married people are more likely than single people (54\% versus $47 \%$ ). Non-US citizens and US citizens have similar intention to vaccinate.

\section{Experimental Results}

Before proceeding to the primary analysis, I display the distribution of responses by treatment in figure 1 panel A. The "yes" share is lowest for the control group, although the differences between each treatment's yes rate and the control are visibly small. The largest mean difference is for the Safety-for-Others message, where the yes-rate is higher than the control by just over 8 percentage points. Similarly, the "no" response rate is higher in the control arm than in any of the treatments, although again the differences are modest ${ }^{8}$

Regressions for the full sample are reported in table 2 None of the four messages have a statistically significant effect on the full sample. Point estimates vary somewhat: the risk-focused messages have estimated effect on the yes-rate ranging from slightly less than zero to just under five percentage points across specifications, while the Safety-for-Self message has an effect of four to six percentage points, and the Safety-for-Others treatment has point estimates of seven to eight percentage points. However, none of these effect sizes are statistically different from the control group, nor are they of the magnitude required for rejection of the null under the preregistered power calculations. Further, an effect of eight percentage points on a baseline vaccination rate of

\footnotetext{
${ }^{8}$ Respondents are offered a "maybe" option to avoid a forced decision between "yes" and "no." I think it is unlikely that moving subjects from a "no" answer to uncertainty predicts much actual increase in vaccine uptake rates. But table A2 in the appendix presents an alternative regression specification where the dependent variable is equal to 0 for "no" answers, $1 \frac{1}{2}$ for "maybe / I don't know" and 1 for "yes." Estimated treatment effects are little changed compared the binary outcome regressions.
} 
$47 \%$ would not be enough to achieve herd immunity.9

\subsection{Treatment effects vary substantially by race and ethnicity}

While the population-level effects are not statistically significant, they conceal important heterogeneity by race and ethnicity.

I divide the sample into two subgroups: one of respondents whose race is reported as whiteonly and of no Hispanic or Latino ethnicity, and one of respondents of Hispanic/Latino ethnicity or indicating a non-white racial identity ${ }^{10}$ I then reestimate the weighted least squares regression for these two subgroups. These estimates are reported in table 3 .

The effects of messaging on white non-Hispanics is quite small. Four of the eight treatment point estimates are negative, and six of the eight estimates are between +2 and -2 percentage points. In column 2, where the addition of control variables improves the precision of the estimates, all $95 \%$ confidence intervals exclude effects larger than 10.1 percentage points.

Hispanic and non-white respondents have much larger estimated effects for three of the treatments. The Safety-for-Self and Risk-to-Others treatments have estimated effects over 10 percentage points, although these are not consistently different from zero at the $5 \%$ significance level. More strikingly, the Safety-for-Others message increases the share of Hispanic and nonwhite respondents who say "yes" by 19 to 22 percentage points, an estimate that is statistically different from zero at the $5 \%$ level in both specifications, both separately and in a joint test adjusted for multiple hypotheses ${ }^{11}$

These differences are clearly visible if we replot the response distribution by race and ethnicity. In figure 2B, the "yes" share among non-Hispanic whites is almost indistinguishable across treatment arms, with the possible exception of the risk-to-self treatment, where it is slightly larger. Contrast this with the large differences in the "yes" rate by message in figure $2 \mathrm{C}$, where the Safety-for-Others share of "yes" excluding non-Hispanic whites is much larger than for the control group's, primarily because of a much smaller share indicating that they are unsure about their response. The proportion of Safety-for-Others respondents who intend to get the vaccine $(56.1 \%)$ is over $50 \%$ higher than in the control group $(37.2 \%)$.

Regressions dividing the sample by political party, sex, and age do not reveal any notable heterogeneity on these dimensions. These additional regressions are reported in appendix A1

\footnotetext{
${ }^{9}$ A commonly cited estimate of the herd immunity threshold for the United States is $70 \%$ of the population Kwok et al. 2020).

${ }^{10}$ That is, respondents are placed in the second group if they are white and Hispanic/Latino, or if they identify as both white and another race.

${ }^{11}$ There are too few respondents assigned to each treatment arm to test effects on particular race and ethnicity groups with precision, but means comparison suggests that this effect is not driven by the responses of just one subgroup. The share of respondents who answer "yes" if they see the safety-for-others message, relative to the control, is $20.5 \%$ points higher for Latino and Hispanic respondents, 18.4\%-points higher for Black respondents, and 31\%-points higher for Asian respondents; this compares to a difference of $1.5 \%$-points among white, non-Hispanic respondents. The mean difference for Native Americans and Alaska Natives is $-2.8 \%$.
} 


\subsection{People are afraid the vaccine will not be safe}

If respondents did not answer that they wanted to vaccinate against COVID-19, a follow-up question asked them to indicate the reason for their answer. Six prewritten reasons for vaccine refusal were offered, as well as space to offer a reason not listed. Respondents were allowed to choose more than one reason of refusal.

Table 4 reports the distribution of these responses by type of refusal and by race/ethnicity. The primary reason for vaccine hesitancy was safety concerns. Over half of the respondents who did not choose "yes" indicated worry that the COVID-19 vaccine would not be safe, including nearly $70 \%$ of respondents who answered "no." This concern was lower in white, non-Hispanic respondents (48\%) than other respondents (55\%).

Other important reasons for refusal or hesitancy included lack of concern about the coronavirus (21\%) and worry that the vaccine would be too expensive (19\%). These two reasons were noticeably different by race and ethnicity: lack of concern was almost twice as high among white, non-Hispanic respondents $(27 \%)$ as others $(14 \%)$, while cost concerns were much higher among non-white and Hispanic respondents (24\%) than among non-Hispanic whites (16\%). Respondents who were uninterested in the vaccine because of anti-vaccine sentiments generally, preexisting health conditions, or previous COVID infection each made up less than $7 \%$ of the non-yes responses.

A substantial number of the respondents, $29 \%$ of the hesitaters, indicated that they were hesitant for a reason not listed, and given space to write out their other reasons. Essentially none of these written comments suggested a reason overlooked by the prewritten responses. Instead, these responses either clarified an ambiguous response to particular prewritten answers (e.g. medical inability to take the vaccine only if it contains certain ingredients) or offering more detailed versions of the prewritten answers (e.g. three respondents wrote that they distrust the vaccine specifically because of conspiracy theories around the support of Bill Gates).

\section{Discussion and conclusion}

This study has important limitations. First, self-reported intention to vaccinate may not be predictive of actual uptake decisions (Leventhal et al. 1965; Falco and Zaccagni 2020). Yet, until an actual vaccine against COVID is available, uptake is hypothetical anyway. It is therefore prudent to design initial messaging based on self-reported intention-to-vaccinate surveys such as this one, and then reassess when actual uptake can be observed.

Second, the primary positive finding of this paper - that messages emphasizing the role of vaccines in safely protecting others is effective among non-white and Hispanic populations - is a post hoc finding ${ }^{12}$ A follow-up experiment designed to study this population specifically should be conducted to confirm and better understand this effect.

\footnotetext{
${ }^{12}$ While the pre-registered analysis described in general terms an intent to estimate heterogeneous treatment effects by subgroups including race and ethnicity, gender, age, and partisanship, it left the exact implementation to be determined depending on the ultimate characteristics of the survey sample.
} 
Despite these limitations, the effectiveness of this message for this group is plausible and, if valid, socially important. Black Americans in particular expect mistreatment and distrust claims of safety from the US health care system; such beliefs are predictive of dangerous underuse of health care resources (Alsan and Wanamaker 2017). Measures to persuade this group to vaccinate are also likely to have outsize importance given that infection and death rates from COVID-19 are much higher for Latinos, Native Americans, and Black Americans (Yancy 2020 Tai et al. 2020), and because vaccine hesitancy is highest for these groups (table 11. Such a strategy could potentially complement a "precision public health strategy" that implements targeted interventions for greater overall effectiveness (Rasmussen et al. 2020).

Messaging aside, this study has also shown that people of color disproportionately hesitate to vaccinate against COVID-19 because of concerns about vaccine safety and affordable access (table 4). Both of these reasons can be addressed with good public policy. Given the ongoing economic turmoil the pandemic has caused, programs to subsidize and widely distribute vaccine doses to willing but price-sensitive groups are likely to pass a cost-benefit analysis easily. And transparent safety testing of candidate vaccines, and effective messaging of that safety and the role of vaccines in protecting families and communities, is likely to be critical for encouraging the broadest possible uptake and protecting as many people as possible, particularly people of color.

\section{References}

Abel, M., Byker, T., and Carpenter, J. (2020). Prosocial behavior in the time of Corona-the effect of role models. IZA Discussion Paper 13560.

Akesson, J., Ashworth-Hayes, S., Hahn, R., Metcalfe, R., and Rasooly, I. (2020). Fatalism, beliefs, and behaviors during the COVID-19 pandemic. NBER Working Paper 27245.

Alsan, M. and Wanamaker, M. (2017). Tuskegee and the Health of Black Men. The Quarterly fournal of Economics, 133(1):407-455.

Andreoni, J. (1995). Warm-Glow versus Cold-Prickle: The Effects of Positive and Negative Framing on Cooperation in Experiments. The Quarterly fournal of Economics, 110(1):1-21.

Brewer, N. T., Chapman, G. B., Rothman, A. J., Leask, J., and Kempe, A. (2017). Increasing vaccination: Putting psychological science into action. Psychological Science in the Public Interest, 18(3):149-207. PMID: 29611455.

Campos-Mercade, P., Meier, A. N., Schneider, F. H., and Wengström, E. (2020). Prosociality predicts health behaviors during the COVID-19 pandemic. University of Zurich Working Paper 346.

Colgrove, J. (2006). State of Immunity: The Politics of Vaccination in Twentieth-Century America. University of California Press and Milbank Memorial Fund.

Falco, P. and Zaccagni, S. (2020). Promoting social distancing in a pandemic: Beyond the good intentions. OSF Preprints. 
Gørtz, M., Brewer, N. T., Hansen, P. R., and Ejrnæs, M. (2020). The contagious nature of a vaccine scare: How the introduction of HPV vaccination lifted and eroded MMR vaccination in Denmark. Vaccine, 38(28):4432 - 4439.

Kolstad, J. T. and Kowalski, A. E. (2012). The impact of health care reform on hospital and preventive care: Evidence from Massachusetts. Journal of Public Economics, 96(11):909 - 929.

Kwok, K. O., Lai, F., Wei, W. I., Wong, S. Y. S., and Tang, J. W. (2020). Herd immunity - estimating the level required to halt the COVID-19 epidemics in affected countries. Fournal of Infection, 80(6):e32-e33.

Leventhal, H., Singer, R., and Jones, S. (1965). Effects of fear and specificity of recommendation upon attitudes and behavior. Fournal of Personality and Social Psychology, 2(1):20-29.

Opel, D., Heritage, J., Taylor, J., Mangione-Smith, R., Salas, H., DeVere, V., Zhou, C., and Robinson, J. (2013). The architecture of provider-parent vaccine discussions at health supervision visits. Pediatrics, 132(6):1037-1046.

Oster, E. (2018). Does disease cause vaccination? Disease outbreaks and vaccination response. Journal of Health Economics, 57:90 - 101.

Rasmussen, S. A., Khoury, M. J., and del Rio, C. (2020). Precision Public Health as a Key Tool in the COVID-19 Response. FAMA.

Reich, J. A. (2018). Calling the shots: Why parents reject vaccines. NYU Press.

Schaller, J., Schulkind, L., and Shapiro, T. (2019). Disease outbreaks, healthcare utilization, and on-time immunization in the first year of life. Journal of Health Economics, 67:102212.

Shoji, M., Cato, S., Iida, T., Ishida, K., Ito, A., and McElwain, K. (2020). COVID-19 and social distancing in the absence of legal enforcement: Survey evidence from Japan. MPRA Paper 100723.

Sjåstad, H. and Van Bavel, J. J. (2020). The best-case heuristic in risk prediction: Hopes and fears in a global health pandemic (COVID-19). PsyArXiv.

Sorensen, A. (2019). The effects of externality distribution and framing on individual vaccination decisions: Experimental evidence. Economics Bulletin, 39(4):2792-2812.

Tai, D. B. G., Shah, A., Doubeni, C. A., Sia, I. G., and Wieland, M. L. (2020). The Disproportionate Impact of COVID-19 on Racial and Ethnic Minorities in the United States. Clinical Infectious Diseases. ciaa815.

Thunstrom, L., Ashworth, M., Finnoff, D., and Newbold, S. (2020). Hesitancy towards a COVID-19 vaccine and prospects for herd immunity. SSRN Electronic fournal. 
Troesken, W. (2015). The Pox of Liberty: How the Constitution Left Americans Rich, Free, and Prone to Infection. University of Chicago Press.

Yancy, C. W. (2020). COVID-19 and African Americans. JAMA, 323(19):1891-1892. 
Table 1: Summary Statistics

\begin{tabular}{|c|c|c|c|}
\hline Respondent Group & Unweighted Count & Weighted Share & Share "Yes" \\
\hline \multicolumn{4}{|l|}{ Do you want the COVID-19 vaccine? } \\
\hline Yes & 1023 & $50.6 \%$ & \\
\hline No & 598 & 19.5 & \\
\hline Maybe / I don't know & 715 & 29.9 & \\
\hline \multicolumn{4}{|l|}{ March 2020: Probability of vaccination } \\
\hline Probability $=0 \%$ & 394 & 8.0 & $4.4 \%$ \\
\hline $1-99 \%$ & 1395 & 47.4 & 38.5 \\
\hline $100 \%$ & 547 & 44.6 & 71.6 \\
\hline Message experiment control group & 466 & 20.8 & 46.6 \\
\hline Treatment group: Risk to Self & 473 & 20.9 & 49.1 \\
\hline Safety for Self & 469 & 18.8 & 52.6 \\
\hline Risk to Others & 461 & 19.9 & 50.3 \\
\hline Safety for Others & 467 & 19.5 & 54.8 \\
\hline Race is white only & 1782 & 76.7 & 53.5 \\
\hline Black only & 216 & 12.7 & 24.6 \\
\hline American/Alaskan Native only & 56 & 0.9 & 19.2 \\
\hline Asian only & 120 & 5.6 & 74.9 \\
\hline Hawaiian/Pacific Islander only & 21 & 0.1 & 57.7 \\
\hline More than one race & 123 & 3.3 & 52.1 \\
\hline Race not reported & 18 & 0.7 & 42.6 \\
\hline Hispanic / Latino ethnicity & 370 & 16.7 & 47.5 \\
\hline White, Non-Hispanic & 1519 & 62.6 & 54.5 \\
\hline Non-white or Hispanic & 817 & 37.4 & 44.0 \\
\hline \multicolumn{4}{|l|}{ Fanuary 2020: Political Party } \\
\hline Democratic & 692 & 30.0 & 57.2 \\
\hline Republican & 635 & 24.5 & 47.0 \\
\hline Independent & 415 & 16.9 & 56.1 \\
\hline Minor Party & 25 & 1.0 & 30.6 \\
\hline Not in UAS 221 survey & 314 & 15.7 & 48.5 \\
\hline Education is less than high school & 107 & 7.2 & 35.2 \\
\hline High school & 989 & 47.0 & 41.8 \\
\hline Associate's degree & 353 & 11.0 & 46.3 \\
\hline Bachelor's degree & 523 & 19.1 & 61.5 \\
\hline Graduate degree & 364 & 15.7 & 73.5 \\
\hline Age $18-29$ & 234 & 12.7 & 46.7 \\
\hline 30-39 & 414 & 25.1 & 41.6 \\
\hline $40-49$ & 451 & 15.8 & 46.7 \\
\hline $50-59$ & 506 & 16.6 & 52.5 \\
\hline $60-69$ & 437 & 17.6 & 54.7 \\
\hline $70+$ & 293 & 12.3 & 69.6 \\
\hline Female & 1418 & 51.6 & 44.4 \\
\hline Male & 918 & 48.4 & 57.2 \\
\hline Married & 1263 & 54.3 & 53.9 \\
\hline Not Married & 1073 & 45.7 & 46.7 \\
\hline US citizen & 2278 & 97.6 & 50.5 \\
\hline Non-US citizen & 58 & 2.4 & 52.6 \\
\hline
\end{tabular}

Columns report the unweighted counts and survey-weighted share of respondents in each category, and the weighted share of each answering "yes" to the vaccination question. 
Table 2: Intention to Vaccinate by Treatment

\begin{tabular}{lcccc}
\hline & $(1)$ & $(2)$ & $(3)$ & $(4)$ \\
\cline { 2 - 5 } Risk to Self & 0.025 & 0.009 & 0.047 & 0.032 \\
& $(0.048)$ & $(0.042)$ & $(0.043)$ & $(0.040)$ \\
Safety for Self & & & & \\
& 0.060 & 0.050 & 0.053 & 0.046 \\
& $(0.049)$ & $(0.043)$ & $(0.043)$ & $(0.040)$ \\
Risk to Others & & & & \\
& 0.037 & 0.017 & 0.014 & -0.001 \\
& $(0.049)$ & $(0.046)$ & $(0.045)$ & $(0.043)$ \\
Safety for Others & & & & \\
& 0.082 & 0.084 & 0.075 & 0.076 \\
Constant & $(0.048)$ & $(0.044)$ & $(0.043)$ & $(0.040)$ \\
& & & & \\
& $0.466^{* *}$ & $0.882^{* *}$ & -0.012 & $0.271^{*}$ \\
Demographic Controls & $(0.034)$ & $(0.121)$ & $(0.045)$ & $(0.124)$ \\
Vaccine Intent Controls & & & & \\
MHT-adjusted F-test p-value & 0.497 & 0.305 & 0.413 & 0.288 \\
\hline
\end{tabular}

Notes:

** $-p<0.01$

* $-p<0.05$

Each column reports a linear probability model regressing whether a respondent answered "Yes" regarding intention to vaccinate against COVID-19 (coded 1) or chose "No" or "Don't Know / Unsure" (coded 0). Demographic controls include sex, age, race, ethnicity, political partisanship, US citizenship, marriage, and education. Vaccine intent controls include the self-reported probability of vaccination as of March 2020 in a prior wave of the UAS survey, included as both a continuous variable and with indicators for probabilities equal to 0 or 1 . A reported p-value at the bottom of the table is for a joint F-test that any of the four treatment variables are significantly different from zero. All regressions are weighted using survey probability weights. 
Table 3: Intention to Vaccinate by Treatment and Race and Ethnicity

\begin{tabular}{|c|c|c|c|c|}
\hline & \multicolumn{2}{|c|}{ White, Non-Hispanic } & \multicolumn{2}{|c|}{ Non-white or Hispanic } \\
\hline & (1) & (2) & (3) & (4) \\
\hline Risk to Self & $\begin{array}{c}0.063 \\
(0.057)\end{array}$ & $\begin{array}{c}0.008 \\
(0.048)\end{array}$ & $\begin{array}{l}-0.035 \\
(0.078)\end{array}$ & $\begin{array}{c}0.062 \\
(0.068)\end{array}$ \\
\hline Safety for Self & $\begin{array}{c}0.019 \\
(0.058)\end{array}$ & $\begin{array}{c}0.001 \\
(0.048)\end{array}$ & $\begin{array}{c}0.113 \\
(0.087)\end{array}$ & $\begin{array}{l}0.159^{*} \\
(0.072)\end{array}$ \\
\hline Risk to Others & $\begin{array}{l}-0.002 \\
(0.060)\end{array}$ & $\begin{array}{l}-0.061 \\
(0.051)\end{array}$ & $\begin{array}{c}0.101 \\
(0.083)\end{array}$ & $\begin{array}{c}0.109 \\
(0.074)\end{array}$ \\
\hline Safety for Others & $\begin{array}{c}0.015 \\
(0.058)\end{array}$ & $\begin{array}{l}-0.005 \\
(0.048)\end{array}$ & $\begin{array}{l}0.188^{*} \\
(0.083)\end{array}$ & $\begin{array}{l}0.215^{* *} \\
(0.070)\end{array}$ \\
\hline Constant & $\begin{array}{l}0.526^{* *} \\
(0.041)\end{array}$ & $\begin{array}{c}0.120 \\
(0.106)\end{array}$ & $\begin{array}{l}0.373^{* *} \\
(0.056)\end{array}$ & $\begin{array}{c}0.099 \\
(0.145)\end{array}$ \\
\hline $\begin{array}{l}\text { Observations } \\
\text { Demographic Controls } \\
\text { Vaccine Intent Controls } \\
\text { MHT-adjusted F-test p-value }\end{array}$ & 1519 & $\begin{array}{c}1519 \\
\checkmark \\
\checkmark \\
0.684\end{array}$ & 0.048 & $\begin{array}{c}817 \\
\checkmark \\
\checkmark \\
0.024\end{array}$ \\
\hline $\begin{array}{l}\text { Notes: } \\
{ }^{*}-p<0.01 \\
*-p<0.05 \\
\text { Regressions are identical to those ir } \\
\text { political party, marriage, and educ } \\
\text { Hispanic respondents, defined as } p \\
\text { indicate Hispanic or Latino ethnicit } \\
\text { are not white and non-Hispanic. }\end{array}$ & $\begin{array}{l}\text { able } 2 \text { exc } \\
\text { ion. The } \\
\text { sons who } \\
\text { "Non-whe }\end{array}$ & $\begin{array}{l}\text { at demogra } \\
\text { wo models } \\
\text { ce is classifi } \\
\text { Hispanic re }\end{array}$ & $\begin{array}{l}\text { c controls } \\
\text { estimatec } \\
\text { as "white } \\
\text { ndents" a }\end{array}$ & $\begin{array}{l}\text { ted to sex, age, } \\
\text { or white, non- } \\
\text { d who do not } \\
\text { pondents who }\end{array}$ \\
\hline
\end{tabular}


Table 4: Reasons People Say Do Not Say “Yes"

\begin{tabular}{|c|c|c|c|c|c|}
\hline & \multicolumn{3}{|c|}{ Vaccine Response } & \multicolumn{2}{|c|}{ Race and Ethnicity } \\
\hline & No & Maybe & Both & $\begin{array}{l}\text { Non-Hispanic } \\
\text { White }\end{array}$ & $\begin{array}{l}\text { Hispanic or } \\
\text { Non-white }\end{array}$ \\
\hline $\begin{array}{l}\text { I do not believe the COVID-19 } \\
\text { vaccine will be safe }\end{array}$ & $67.9 \%$ & $39.3 \%$ & $50.6 \%$ & $47.5 \%$ & $54.9 \%$ \\
\hline $\begin{array}{l}\text { I am not very concerned about } \\
\text { the coronavirus }\end{array}$ & 30.4 & 15.5 & 21.4 & 26.6 & 14.3 \\
\hline $\begin{array}{l}\text { I expect the cost of the vaccine } \\
\text { will be too high }\end{array}$ & 10.4 & 25.3 & 19.4 & 15.9 & 24.2 \\
\hline $\begin{array}{l}\text { I oppose all vaccines because of } \\
\text { religious or personal beliefs }\end{array}$ & 14.0 & 1.2 & 6.3 & 5.9 & 6.8 \\
\hline $\begin{array}{l}\text { I have a health condition and } \\
\text { cannot receive vaccines }\end{array}$ & 5.6 & 3.7 & 4.4 & 5.2 & 3.4 \\
\hline $\begin{array}{l}\text { I have had COVID-19 and I am } \\
\text { already immune }\end{array}$ & 3.4 & 1.1 & 2.0 & 1.0 & 3.4 \\
\hline Another reason not listed here & 14.6 & 38.3 & 28.9 & 33.2 & 23.2 \\
\hline
\end{tabular}

Columns report the share of respondents indicating reasons they did not select "yes" to the question asking whether they wanted to vaccinate against COVID-19. Respondents were permitted to indicate more than one reason and totals sum to more than 100 percent. Respondent shares are reported separately and pooled for the 598 "no" responses and 715 "Maybe / I don’t know” responses. Proportions are weighted averages using survey weights. 
Figure 1: Response Distribution by Treatment and Race/Ethnicity

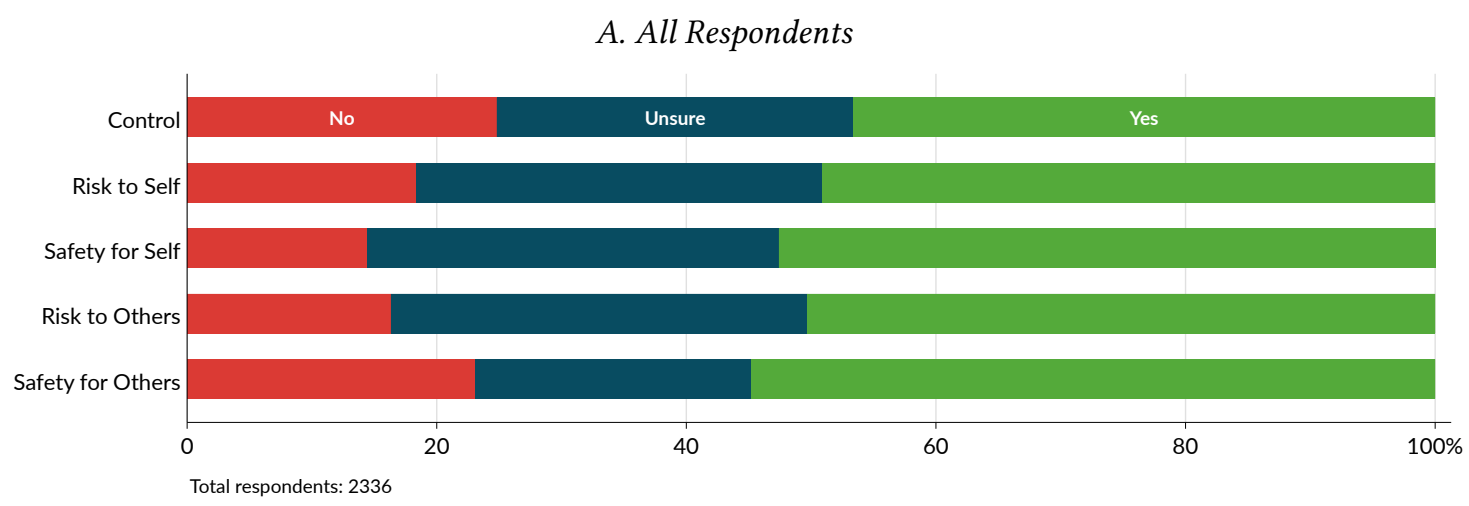

B. White, Non-Hispanic Respondents

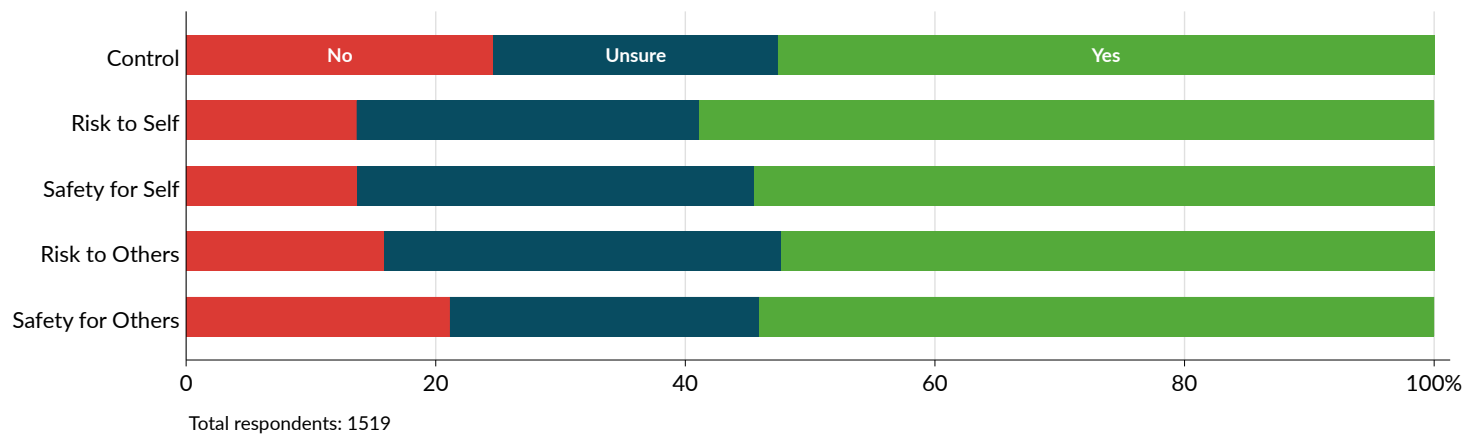

C. Non-White or Hispanic Respondents

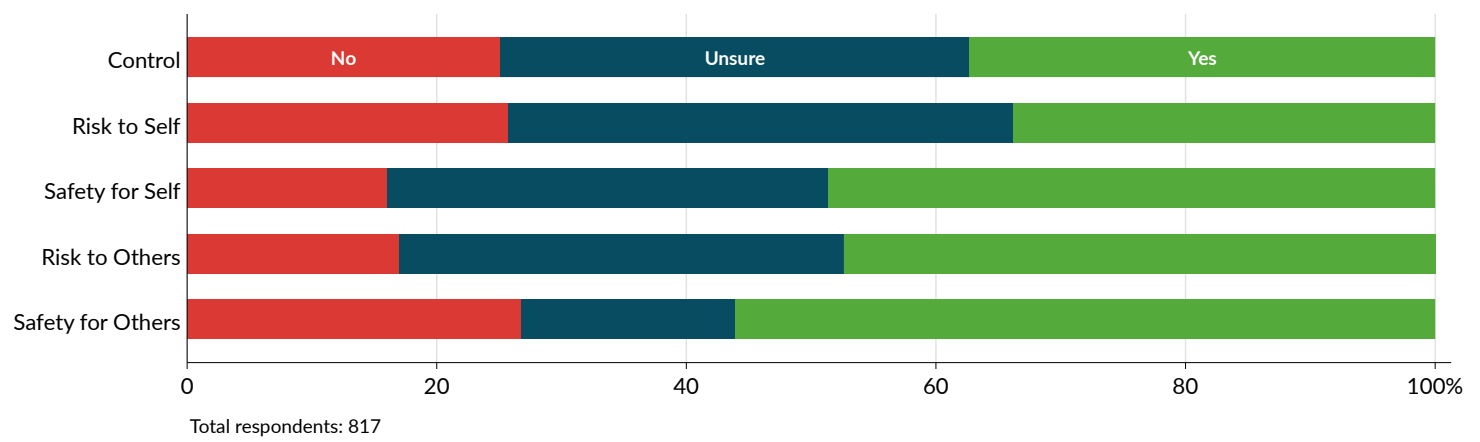

Notes: Panel A displays response by treatment for all respondents. Panel B displays proportions by treatment for white, non-Hispanic respondents, defined as persons whose race is classified as "white only" and who do not indicate Hispanic or Latino ethnicity. Panel C reports responses by treatment for all other respondents. Proportions are weighted by survey weights. 
Appendices

For Online Publication 


\section{A1 Additional Regressions}

Table A1: Unweighted Regressions

\begin{tabular}{|c|c|c|c|c|c|c|}
\hline & \multicolumn{2}{|c|}{ All Respondents } & \multicolumn{2}{|c|}{ White, Non-Hispanic } & \multicolumn{2}{|c|}{ Non-white or Hispanic } \\
\hline & (1) & $(2)$ & (3) & $(4)$ & (5) & (6) \\
\hline Risk to Self & $\begin{array}{c}0.032 \\
(0.032)\end{array}$ & $\begin{array}{c}0.043 \\
(0.028)\end{array}$ & $\begin{array}{c}0.010 \\
(0.040)\end{array}$ & $\begin{array}{c}0.009 \\
(0.034)\end{array}$ & $\begin{array}{c}0.071 \\
(0.054)\end{array}$ & $\begin{array}{c}0.095 \\
(0.049)\end{array}$ \\
\hline Safety for Self & $\begin{array}{c}0.068^{*} \\
(0.032)\end{array}$ & $\begin{array}{c}0.061^{*} \\
(0.028)\end{array}$ & $\begin{array}{c}0.024 \\
(0.040)\end{array}$ & $\begin{array}{c}0.008 \\
(0.033)\end{array}$ & $\begin{array}{l}0.149^{* *} \\
(0.055)\end{array}$ & $\begin{array}{l}0.157^{* *} \\
(0.050)\end{array}$ \\
\hline Risk to Others & $\begin{array}{c}0.037 \\
(0.033)\end{array}$ & $\begin{array}{c}0.022 \\
(0.028)\end{array}$ & $\begin{array}{c}0.004 \\
(0.041)\end{array}$ & $\begin{array}{l}-0.025 \\
(0.035)\end{array}$ & $\begin{array}{c}0.099 \\
(0.053)\end{array}$ & $\begin{array}{c}0.100^{*} \\
(0.048)\end{array}$ \\
\hline Safety for Others & $\begin{array}{c}0.068^{*} \\
(0.032)\end{array}$ & $\begin{array}{c}0.065^{*} \\
(0.028)\end{array}$ & $\begin{array}{c}0.033 \\
(0.041)\end{array}$ & $\begin{array}{c}0.015 \\
(0.034)\end{array}$ & $\begin{array}{c}0.130^{*} \\
(0.054)\end{array}$ & $\begin{array}{l}0.160^{* *} \\
(0.049)\end{array}$ \\
\hline Constant & $\begin{array}{l}0.397^{* *} \\
(0.023)\end{array}$ & $\begin{array}{l}0.261^{* *} \\
(0.058)\end{array}$ & $\begin{array}{l}0.439^{* *} \\
(0.029)\end{array}$ & $\begin{array}{c}0.137^{*} \\
(0.069)\end{array}$ & $\begin{array}{l}0.321^{* *} \\
(0.038)\end{array}$ & $\begin{array}{c}-0.003 \\
(0.115)\end{array}$ \\
\hline Observations & 2336 & 2336 & 1519 & 1519 & 817 & 817 \\
\hline Demographic Controls & & $\checkmark$ & & $\checkmark$ & & $\checkmark$ \\
\hline Vaccine Intent Controls & & $\checkmark$ & & $\checkmark$ & & $\checkmark$ \\
\hline MHT-adjusted F-test $\mathrm{p}$-value & 0.193 & 0.102 & 0.914 & 0.794 & 0.061 & 0.007 \\
\hline
\end{tabular}




\section{Table A2: Vaccine Hesitancy Score Regressions}

\begin{tabular}{|c|c|c|c|c|c|c|}
\hline & \multicolumn{2}{|c|}{ All Respondents } & \multicolumn{2}{|c|}{ White, Non-Hispanic } & \multicolumn{2}{|c|}{ Non-white or Hispanic } \\
\hline & (1) & $(2)$ & (3) & (4) & $(5)$ & (6) \\
\hline Risk to Self & $\begin{array}{c}0.045 \\
(0.037)\end{array}$ & $\begin{array}{c}0.059^{*} \\
(0.029)\end{array}$ & $\begin{array}{c}0.086 \\
(0.044)\end{array}$ & $\begin{array}{c}0.050 \\
(0.036)\end{array}$ & $\begin{array}{c}-0.021 \\
(0.062)\end{array}$ & $\begin{array}{c}0.066 \\
(0.047)\end{array}$ \\
\hline Safety for Self & $\begin{array}{c}0.082^{*} \\
(0.037)\end{array}$ & $\begin{array}{l}0.073^{*} \\
(0.029)\end{array}$ & $\begin{array}{c}0.064 \\
(0.044)\end{array}$ & $\begin{array}{c}0.047 \\
(0.035)\end{array}$ & $\begin{array}{c}0.102 \\
(0.064)\end{array}$ & $\begin{array}{l}0.133^{*} \\
(0.053)\end{array}$ \\
\hline Risk to Others & $\begin{array}{c}0.061 \\
(0.038)\end{array}$ & $\begin{array}{c}0.028 \\
(0.031)\end{array}$ & $\begin{array}{c}0.043 \\
(0.047)\end{array}$ & $\begin{array}{l}-0.004 \\
(0.037)\end{array}$ & $\begin{array}{c}0.091 \\
(0.063)\end{array}$ & $\begin{array}{c}0.084 \\
(0.053)\end{array}$ \\
\hline Safety for Others & $\begin{array}{c}0.049 \\
(0.039)\end{array}$ & $\begin{array}{c}0.049 \\
(0.031)\end{array}$ & $\begin{array}{c}0.025 \\
(0.047)\end{array}$ & $\begin{array}{c}0.004 \\
(0.038)\end{array}$ & $\begin{array}{c}0.086 \\
(0.069)\end{array}$ & $\begin{array}{c}0.121^{*} \\
(0.055)\end{array}$ \\
\hline Constant & $\begin{array}{l}0.609^{* *} \\
(0.027)\end{array}$ & $\begin{array}{l}0.427^{* *} \\
(0.064)\end{array}$ & $\begin{array}{l}0.640^{* *} \\
(0.034)\end{array}$ & $\begin{array}{l}0.265^{* *} \\
(0.083)\end{array}$ & $\begin{array}{l}0.561^{* *} \\
(0.044)\end{array}$ & $\begin{array}{l}0.308^{* *} \\
(0.106)\end{array}$ \\
\hline Observations & 2336 & 2336 & 1519 & 1519 & 817 & 817 \\
\hline Demographic Controls & & $\checkmark$ & & $\checkmark$ & & $\checkmark$ \\
\hline Vaccine Intent Controls & & $\checkmark$ & & $\checkmark$ & & $\checkmark$ \\
\hline MHT-adjusted F-test p-value & 0.263 & 0.105 & 0.325 & 0.311 & 0.164 & 0.098 \\
\hline
\end{tabular}

** $-p<0.01$

* $-p<0.05$

Regressions are identical to those in table 2 (columns 1 and 4) and table 3 except that the dependent variable is equal to one-half for respondents who chose "Maybe / I Don't Know." Responses of "Yes" are still coded 1 and "No" coded 0. 
Table A3: Intention to Vaccinate by Age Group

\begin{tabular}{|c|c|c|c|c|}
\hline & \multicolumn{2}{|c|}{ Age 18 to 51} & \multicolumn{2}{|c|}{ Age $>51$} \\
\hline & (1) & (2) & (3) & (4) \\
\hline Risk to Self & $\begin{array}{c}0.056 \\
(0.064)\end{array}$ & $\begin{array}{c}0.040 \\
(0.053)\end{array}$ & $\begin{array}{l}-0.016 \\
(0.069)\end{array}$ & $\begin{array}{c}0.026 \\
(0.058)\end{array}$ \\
\hline Safety for Self & $\begin{array}{c}0.124 \\
(0.066)\end{array}$ & $\begin{array}{c}0.088 \\
(0.054)\end{array}$ & $\begin{array}{l}-0.027 \\
(0.070)\end{array}$ & $\begin{array}{l}-0.005 \\
(0.056)\end{array}$ \\
\hline Risk to Others & $\begin{array}{c}0.087 \\
(0.066)\end{array}$ & $\begin{array}{c}0.011 \\
(0.056)\end{array}$ & $\begin{array}{l}-0.024 \\
(0.072)\end{array}$ & $\begin{array}{c}-0.021 \\
(0.064)\end{array}$ \\
\hline Safety for Others & $\begin{array}{c}0.126 \\
(0.065)\end{array}$ & $\begin{array}{c}0.074 \\
(0.055)\end{array}$ & $\begin{array}{c}0.023 \\
(0.069)\end{array}$ & $\begin{array}{c}0.077 \\
(0.056)\end{array}$ \\
\hline Constant & $\begin{array}{c}0.370^{* *} \\
(0.045)\end{array}$ & $\begin{array}{c}0.258 \\
(0.135)\end{array}$ & $\begin{array}{l}0.593^{* *} \\
(0.049)\end{array}$ & $\begin{array}{c}0.103 \\
(0.228)\end{array}$ \\
\hline $\begin{array}{l}\text { Observations } \\
\text { Demographic Controls } \\
\text { Vaccine Intent Controls } \\
\text { MHT-adjusted F-test p-value }\end{array}$ & 1206 & $\begin{array}{l}1206 \\
\checkmark \\
\checkmark \\
0.412\end{array}$ & 0.951 & $\begin{array}{c}1130 \\
\checkmark \\
\checkmark \\
0.467\end{array}$ \\
\hline
\end{tabular}

${ }^{* *}-p<0.01$

$*-p<0.05$

The sample is divided into equally sized subsamples at median age 51. Regressions are identical to those in table 2 columns 1 and 4 , except that demographic controls are limited to gender, race, ethnicity, citizenship, marriage, and education. 
Table A4: Intention to Vaccinate by Gender

\begin{tabular}{|c|c|c|c|c|}
\hline & \multicolumn{2}{|c|}{ Female } & \multicolumn{2}{|c|}{ Not Female } \\
\hline & (1) & (2) & (3) & (4) \\
\hline Risk to Self & $\begin{array}{c}0.021 \\
(0.063)\end{array}$ & $\begin{array}{c}0.066 \\
(0.053)\end{array}$ & $\begin{array}{c}0.023 \\
(0.071)\end{array}$ & $\begin{array}{c}0.003 \\
(0.059)\end{array}$ \\
\hline Safety for Self & $\begin{array}{c}0.083 \\
(0.064)\end{array}$ & $\begin{array}{c}0.075 \\
(0.053)\end{array}$ & $\begin{array}{c}0.039 \\
(0.074)\end{array}$ & $\begin{array}{c}0.009 \\
(0.058)\end{array}$ \\
\hline Risk to Others & $\begin{array}{c}0.079 \\
(0.068)\end{array}$ & $\begin{array}{c}0.077 \\
(0.058)\end{array}$ & $\begin{array}{l}-0.018 \\
(0.071)\end{array}$ & $\begin{array}{l}-0.044 \\
(0.059)\end{array}$ \\
\hline Safety for Others & $\begin{array}{c}0.038 \\
(0.064)\end{array}$ & $\begin{array}{c}0.045 \\
(0.053)\end{array}$ & $\begin{array}{c}0.152^{*} \\
(0.070)\end{array}$ & $\begin{array}{c}0.105 \\
(0.059)\end{array}$ \\
\hline Constant & $\begin{array}{l}0.402^{* *} \\
(0.044)\end{array}$ & $\begin{array}{c}0.122 \\
(0.167)\end{array}$ & $\begin{array}{l}0.538^{* *} \\
(0.051)\end{array}$ & $\begin{array}{l}0.354^{*} \\
(0.167)\end{array}$ \\
\hline Observations & 1418 & 1418 & 918 & 918 \\
\hline Demographic Controls & & $\checkmark$ & & $\checkmark$ \\
\hline Vaccine Intent Controls & & $\checkmark$ & & $\checkmark$ \\
\hline MHT-adjusted F-test $p$-value & 0.658 & 0.59 & 0.107 & 0.138 \\
\hline
\end{tabular}


Table A5: Regressions by Party Registration

\begin{tabular}{|c|c|c|c|c|c|c|}
\hline & \multicolumn{2}{|c|}{ Republicans } & \multicolumn{2}{|c|}{ Democrats } & \multicolumn{2}{|c|}{ Others } \\
\hline & (1) & $(2)$ & (3) & (4) & (5) & (6) \\
\hline Risk to Self & $\begin{array}{l}-0.018 \\
(0.096)\end{array}$ & $\begin{array}{l}-0.015 \\
(0.089)\end{array}$ & $\begin{array}{c}0.009 \\
(0.091)\end{array}$ & $\begin{array}{c}-0.016 \\
(0.076)\end{array}$ & $\begin{array}{c}0.054 \\
(0.069)\end{array}$ & $\begin{array}{c}0.070 \\
(0.053)\end{array}$ \\
\hline Safety for Self & $\begin{array}{c}0.023 \\
(0.096)\end{array}$ & $\begin{array}{l}-0.024 \\
(0.084)\end{array}$ & $\begin{array}{c}0.035 \\
(0.093)\end{array}$ & $\begin{array}{c}0.039 \\
(0.068)\end{array}$ & $\begin{array}{c}0.094 \\
(0.072)\end{array}$ & $\begin{array}{c}0.077 \\
(0.059)\end{array}$ \\
\hline Risk to Others & $\begin{array}{c}0.059 \\
(0.098)\end{array}$ & $\begin{array}{l}-0.008 \\
(0.077)\end{array}$ & $\begin{array}{c}0.018 \\
(0.090)\end{array}$ & $\begin{array}{c}-0.034 \\
(0.079)\end{array}$ & $\begin{array}{c}0.018 \\
(0.074)\end{array}$ & $\begin{array}{c}0.004 \\
(0.065)\end{array}$ \\
\hline Safety for Others & $\begin{array}{c}0.086 \\
(0.097)\end{array}$ & $\begin{array}{c}0.062 \\
(0.077)\end{array}$ & $\begin{array}{c}0.128 \\
(0.090)\end{array}$ & $\begin{array}{c}0.112 \\
(0.071)\end{array}$ & $\begin{array}{c}0.047 \\
(0.070)\end{array}$ & $\begin{array}{c}0.072 \\
(0.060)\end{array}$ \\
\hline Constant & $\begin{array}{l}0.439^{* *} \\
(0.070)\end{array}$ & $\begin{array}{l}0.403^{* *} \\
(0.137)\end{array}$ & $\begin{array}{l}0.535^{* *} \\
(0.065)\end{array}$ & $\begin{array}{l}0.440^{* *} \\
(0.145)\end{array}$ & $\begin{array}{l}0.441^{* *} \\
(0.047)\end{array}$ & $\begin{array}{l}0.313^{* *} \\
(0.107)\end{array}$ \\
\hline Observations & 635 & 635 & 692 & 692 & 1009 & 1009 \\
\hline Demographic Controls & & $\checkmark$ & & $\checkmark$ & & $\checkmark$ \\
\hline Vaccine Intent Controls & & $\checkmark$ & & $\checkmark$ & & $\checkmark$ \\
\hline MHT-adjusted F-test $p$-value & 0.806 & 0.797 & 0.591 & 0.25 & 0.746 & 0.521 \\
\hline
\end{tabular}




\section{A2 Text of Survey Experiment}

Question 1, Control Group:

\section{About the COVID-19 Vaccine}

This short survey will ask about your plans to vaccinate against the coronavirus that causes the COVID-19 illness. Right now, there is no vaccine against the coronavirus. However, one may be available in the coming months.

Do you want to get the COVID-19 vaccine?

$\bigcirc$ Yes

$\bigcirc$ No

Maybe / I Don't Know

Choose One. If "Yes," go to question 2. If "No" or "Maybe / I Don't Know," go to question 3. 
Question 1, Risk-to-Self Treatment Group:

\section{About the COVID-19 Vaccine}

This short survey will ask about your plans to vaccinate against the coronavirus that causes the COVID-19 illness. Right now, there is no vaccine against the coronavirus. However, one may be available in the coming months.

The following is a potential message to promote the vaccine when it becomes available:

It is important to vaccinate against COVID-19 because it is dangerous. The virus can harm the lungs, heart, brain, and other body systems. While elderly and ill people are at extra risk, COVID-19 is potentially deadly for anyone. Your vaccination protects you from death or severe illness.

Please read the message above carefully before answering the survey.

Do you want to get the COVID-19 vaccine?

$\bigcirc$ Yes

No

Maybe / I Don't Know

Choose One. If "Yes," go to question 2. If "No" or "Maybe / I Don't Know," go to question 3. 
Question 1, Safe-for-Self Treatment Group:

\section{About the COVID-19 Vaccine}

This short survey will ask about your plans to vaccinate against the coronavirus that causes the COVID-19 illness. Right now, there is no vaccine against the coronavirus. However, one may be available in the coming months.

The following is a potential message to promote the vaccine when it becomes available:

It is important to vaccinate against COVID-19 because it is dangerous. The virus can harm the lungs, heart, brain, and other body systems. Vaccination gives you immunity without illness. Your vaccination can keep you healthy and safe.

Please read the message above carefully before answering the survey.

Do you want to get the COVID-19 vaccine?

$\bigcirc$ Yes

No

Maybe / I Don't Know

Choose One. If "Yes," go to question 2. If "No" or "Maybe / I Don't Know," go to question 3. 
Question 1, Risk-to-Others Treatment Group:

\section{About the COVID-19 Vaccine}

This short survey will ask about your plans to vaccinate against the coronavirus that causes the COVID-19 illness. Right now, there is no vaccine against the coronavirus. However, one may be available in the coming months.

The following is a potential message to promote the vaccine when it becomes available:

It is important to vaccinate against COVID-19 because it is contagious. When a person becomes immune, they will not spread the virus to others. While elderly and ill people are at extra risk, COVID-19 is potentially deadly for everybody. Your vaccination protects others from death or severe illness.

Please read the message above carefully before answering the survey.

Do you want to get the COVID-19 vaccine?

$\bigcirc$ Yes

No

Maybe / I Don't Know

Choose One. If "Yes," go to question 2. If "No" or "Maybe / I Don't Know," go to question 3. 
Question 1, Safe-for-Others Treatment Group:

\section{About the COVID-19 Vaccine}

This short survey will ask about your plans to vaccinate against the coronavirus that causes the COVID-19 illness. Right now, there is no vaccine against the coronavirus. However, one may be available in the coming months.

The following is a potential message to promote the vaccine when it becomes available:

It is important to vaccinate against COVID-19 because it is contagious. When a person becomes immune, they will not spread the virus to others. Vaccination gives you immunity without illness. Your vaccination can keep other people healthy and safe.

Please read the message above carefully before answering the survey.

Do you want to get the COVID-19 vaccine?

$\bigcirc$ Yes

No

Maybe / I Don't Know

Choose One. If "Yes," go to question 2. If "No" or "Maybe / I Don't Know," go to question 3. 
Question 2, For "Yes" Answers to Question 1:

When the vaccine becomes available, how quickly will you want it?

As soon as possible

I want to wait before getting vaccinated

Not sure / I don't know

Choose One. After answer, end survey 
Question 3, For "No" and "Maybe" Answers to Question 1:

You indicated that do not want the COVID vaccine, or that you are not sure. Why not? Check all that apply

$\square$ I have had COVID-19 and I am already immune.

$\square$ I have a health condition and cannot receive vaccines.

$\square$ I oppose all vaccines because of religious or personal beliefs.

$\square$ I do not believe the COVID-19 vaccine will be safe.

$\square$ I expect the cost of the vaccine will be too high.

I am not very concerned about the coronavirus.

Another reason not listed here.

Choose at least one. After answer, end survey 